\title{
Editorial
}

\section{La APP U.D.C.A más cerca de la I+D+i}

\author{
Germán Anzola Montero ${ }^{1}$ \\ Rector \\ ${ }^{1}$ Rector. Universidad de Ciencias Aplicadas y Ambientales U.D.C.A, (Dttps://orcid.org/0000-0001-6075-2595
}

Como citar: Anzola Montero, G. 2021. La APP U.D.C.A más cerca de la I+D+i. Rev. U.D.C.A Act. \& Div. Cient. 24(2):e2172. http://doi. org/10.31910/rudca.v24.n2.2021.2172

Artículo de acceso abierto publicado por Revista U.D.C.A Actualidad \& Divulgación Científica, bajo una licencia Creative Commons CC BY-NC 4.0

Publicación oficial de la Universidad de Ciencias Aplicadas y Ambientales U.D.C.A, Institución de Educación Superior Acreditada de Alta Calidad por el Ministerio de Educación Nacional.

Actualmente, nos encontramos ante una sociedad del conocimiento que, según Krüger (2006), el avance de las tecnologías y las comunicaciones (TIC), permiten un avance tecnológico, abriendo la ventana para renovar los procesos de conocimiento, desarrollo e innovación e incentivar toda la gestión académica, administrativa, corporativa, en el sentido de avanzar en un entorno cambiante y "su utilización en los procesos económicos y en los ámbitos de planificación de la educación y formación, de la organización (gestión de conocimiento) y del trabajo (trabajo de conocimiento), adaptándose las estructuras organizativas y de gestión a un entorno cambiante".

En este sentido, las Universidades, característicamente, no son las únicas que generan conocimiento, ya que otras organizaciones han logrado promover competencias efectivas, con la ayuda de las herramientas virtuales, permitiendo, así, impulsar la conformación de la sociedad del conocimiento (Pulido Huertas \& Najar Sánchez, 2015). Precisamente, que el conocimiento sea invaluable y necesario, incentiva los procesos de innovación en la Educación Superior y la relación que con esto tienen las TIC, resulta determinante.

En ese contexto, se ha potenciado en toda la Educación Superior la inminente incorporación de las Tecnologías de la Información y de la Comunicación (TIC), las cuales, resultan ser una herramienta efectiva para el desarrollo de los procesos misionales, a saber, Formación, Investigación y Extensión y Proyección Social.

Como parte del proceso de innovación e incorporación de nuevas tecnologías en el quehacer universitario, la U.D.C.A adoptó, en este año, el desarrollo de su aplicación, la cual, se caracteriza por ser accesible y con funcionalidad para toda la comunidad universitaria, entre la cual, se encuentra el proceso de investigación y gestión del conocimiento.

Innovar, agilizar y actualizar son los tres verbos que caracterizan a la App U.D.C.A. Por ello, en esta nueva versión y teniendo en cuenta nuestro quehacer investigativo, se dispuso una ventana o sección especial, la cual, le permite a los profesores acceder directamente al micrositio de investigación, donde encuentran información afín con las convocatorias vigentes, tanto internas como externas; mantenerse al día de las noticias relacionadas con la actividad investigativa de la Universidad; conocer a los investigadores y a los grupos de investigación de otros programas académicos y facultades, lo que facilita la articulación entre disciplinas y áreas del conocimiento; adicionalmente, encuentran todas las políticas institucionales, que orientan la actividad investigativa.

La App U.D.C.A, igualmente, les ayuda a llevar el seguimiento y control de sus proyectos de investigación, como el avance en el desarrollo de actividades, ejecución presupuestal, estado de entrega de informes y productos, con lo cual, los investigadores pueden hacer una gestión adecuada de sus proyectos.

Hoy por hoy, todo se maneja a través de celulares o tablets digitales y poder contar con una aplicación que permita la gestión de los proyectos de investigación, convocatorias y productos, facilita el proceso de seguimiento y asegura un buen desarrollo de las actividades investigativas, de innovación y de desarrollo. 
La puesta en marcha con esta App es hacer más fácil y rápida la labor de nuestros científicos y académicos; además, su aplicabilidad se debe constituir en una herramienta tecnológica a la hora de pensar en las investigaciones, en gestionar el tiempo, en incrementar la productividad y organizar la información requerida, entre otras ventajas.

Lo más importante de la App U.D.C.A es la inmediatez para nuestros investigadores, es decir, contar con una aplicación móvil y de bolsillo, que les permita mostrar y dar a conocer, en tiempo real, sus productos científicos, resultado del acervo investigativo.

En este momento, con el uso de la App U.D.C.A, entregamos procesos de mejora, de innovación y vigente en el tiempo, que abarca cada uno de los servicios que presta la Universidad, con la proyección que sea sostenible en el futuro, tanto en el acceso, en la seguridad de los datos como en lo versátil; esto último, teniendo en cuenta lo cambiante de las actualizaciones tecnológicas. Es descubrir lo nuevo de la vida universitaria.

Con esta implementación, nos proponemos construir conocimiento a partir de tecnología, que permita ofrecer soluciones a los problemas del entorno local, regional y nacional, incentivando el espíritu investigativo de todos nuestros profesores, comprendiendo que el mundo interconectado en el que vivimos, demanda de una rápida respuesta a las problemáticas que, a diario, se incrementan.

Este nuevo aporte que la U.D.C.A brinda a toda la comunidad universitaria, expresa su permanente deseo de innovar, facilitar y complementar los sistemas de información, particularmente, los relacionados con la investigación y generación de conocimiento en la comunidad universitaria, todo lo anterior siempre pensando en el mejoramiento continuo de todos los procesos académicos.

\section{REFERENCIAS}

1. KRÜGER, K. 2006. Concepto de la 'Sociedad del Conocimiento'. Biblio 3W, Revista Bibliográfica de Geografía y Ciencias Sociales. 11(683).

2. PULIDO HUERTAS, D.C.; NAJAR SÁNCHEZ, O. 2015. Gestión del conocimiento en educación con tic en la transformación de la escuela. Vínculos. 12(1):41-55. 